\title{
Advantages and Limitations of Focal Liver Lesion Assessment with Ultrasound Contrast Agents: Comments on the European Federation of Societies for Ultrasound in Medicine and Biology (EFSUMB) Guidelines
}

\author{
Liliana Chiorean ${ }^{\mathrm{a}, \mathrm{c}}$ Claudio Tanad Barbara Braden $^{\mathrm{e}}$ Cosmin Caraiani $^{\mathrm{f}}$ \\ Zeno Sparchez $^{g}$ Xin-Wu Cui ${ }^{\text {h }}$ Ulrich Baum ${ }^{\text {b }}$ Christoph F. Dietrich ${ }^{a}$
}

Departments of ${ }^{\mathrm{a}}$ Internal Medicine and ${ }^{\mathrm{b}}$ Radiology, Caritas Hospital, Bad Mergentheim, Germany; ${ }^{\mathrm{c}}$ Department of Medical Imaging, des Cévennes Clinic, Annonay, France; ${ }^{d}$ Internal Medicine Unit, Guastalla Hospital, AUSL Reggio Emilia, Guastalla, Italy; ${ }^{\mathrm{T}}$ Translational Gastroenterology Unit, Oxford University Hospitals, Oxford, UK; Departments of ${ }^{f}$ Radiology and Computed Tomography and ' $\mathrm{G}$ Gastroenterology, 'Octavian Fodor' Institute of Gastroenterology and Hepatology and 'Iuliu Haţieganu' University of Medicine and Pharmacy, Cluj-Napoca, Romania; ${ }^{\text {h} D e p a r t m e n t ~ o f ~}$ Medical Ultrasound, Tongji Hospital, Tongji Medical College, Huazhong University of Science and Technology, Wuhan, China

\section{Key Words}

Guidelines · Focal liver lesions · Contrast-enhanced ultrasound - Computed tomography - Magnetic resonance imaging

\begin{abstract}
Contrast-enhanced ultrasound (CEUS) represents a significant breakthrough in sonography. Due to US contrast agents (UCAs) and contrast-specific techniques, sonography offers the potential to show enhancement of liver lesions in a similar way as contrast-enhanced cross-sectional imaging techniques. The real-time assessment of liver perfusion throughout the vascular phases, without any risk of nephrotoxicity, represents one of the major advantages that this technique offers. CEUS has led to a dramatic improvement in the diagnostic accuracy of US and subsequently has been included in current guidelines as an im-
\end{abstract}

\begin{tabular}{ll}
\hline KARGER & $\begin{array}{l}\text { ( } 2016 \text { S. Karger AG, Basel } \\
1011-7571 / 16 / 0255-0399 \$ 39.50 / 0\end{array}$ \\
$\begin{array}{l}\text { E-Mail karger@karger.com } \\
\text { www.karger.com/mpp }\end{array}$ & $\begin{array}{l}\text { This is an Open Access article licensed under the terms of the } \\
\text { Creative Commons Attribution-NonCommercial 3.0 Un- } \\
\text { ported license (CC BY-NC) (www.karger.com/OA-license), } \\
\text { applicable to the online version of the article only. Distribu- } \\
\text { tion permitted for non-commercial purposes only. }\end{array}$
\end{tabular}

portant step in the diagnostic workup of focal liver lesions (FLLs), resulting in a better patient management and costeffective therapy. The purpose of this review was to provide a detailed description of contrast agents used in different cross-sectional imaging procedures for the study of FLLs, focusing on characteristics, indications and advantages of UCAs in clinical practice.

(c) 2016 S. Karger AG, Basel

\section{Introduction}

Contrast-enhanced ultrasound (CEUS) is a relatively innovative contrast diagnostic procedure. Used for over 10 years, CEUS has been largely implemented in clinical practice being a rapid, noninvasive, cost-effective and simple diagnostic procedure which can be performed at the patient's bedside [1-5]. 
Table 1. Commercially available UCAs

\begin{tabular}{lllll}
\hline Name & Company & Gas & Shell & Main characteristics \\
\hline SonoVue $^{\circledR}$ & Bracco & sulfur hexafluoride & phospholipids & pure blood pool CA \\
Optison $^{\circledR}$ & GE Healthcare & octafluoropropane & human albumin & pure blood pool CA \\
Definity $^{\circledR}$ & Lantheus & octafluoropropane & phospholipids & pure blood pool CA \\
Sonazoid $^{\circledR}$ & GE Healthcare & perfluorobutane & hydrogenated egg phosphatidyl serine & uptake by macrophages and Kupffer cells \\
Levovist $^{\circledR}$ & Schering AG & air & galactose/palmitic acid & uptake by macrophages and Kupffer cells \\
\hline
\end{tabular}

In this review, we have illustrated the advantages and limitations of using US contrast agents (UCAs) in comparison to contrast agents (CAs) used in computed tomography $(\mathrm{CT})$ and magnetic resonance imaging (MRI).

\section{The Basics of UCAs}

UCAs are gas-filled microbubbles stabilized by a shell and administered intravenously in a bolus in small volumes $(0.1-4.8 \mathrm{ml})$. The region of interest is visualized using tissue harmonic imaging and a low mechanical index. UCAs perform as blood pool tracers and enhance the visualization of the parenchymal microvasculature with the best temporal resolution [6]. Even though technological advancements have led to time resolution values of $83 \mathrm{~ms}$ for dual-source CT [7] and of about $35 \mathrm{~ms}$ for MRI $[8,9]$, the advantages of CEUS are due to the practically realtime examination and real-time assessment [10], allowing for a better visualization of enhancement patterns during all phases, without the need of specifically planned time acquisitions. The size of the microbubbles is fairly uniform between 1 and $4 \mu \mathrm{m}$. This means that they are smaller than erythrocytes and flow easily through small capillaries.

Even if the vascular pattern of enhancement is described with the same criteria as in contrast-enhanced CT (CECT) and contrast-enhanced MRI (CEMRI), the examinations are not equivalent due to the different pharmacokinetics of UCAs. In contrast to cross-sectional CAs, which are rapidly cleared from the blood pool into the extracellular space, UCAs are strictly intravascular and do not diffuse into the tumor interstitium $[1,6$, 11-16], allowing for a better characterization of focal liver lesions (FLLs) [17]. Several enhancement patterns can be identified for FLLs after UCA administration. The most commonly observed patterns of enhancement for benign and malignant FLLs are shown in table 1 as previ- ously published $[2,3]$. Issues such as enhancement during the arterial phase, including onset, peripheral or central initial enhancement, homogeneity/heterogeneity of FLL enhancement, as well as presence or absence of portal-venous or late-phase washout should all be assessed, as these parameters are important for the differentiation between malignant and benign FLLs and for a further differential diagnosis [10]. Some examples are shown in figures 1-3.

\section{Characteristics of CT CAs}

Nowadays, nonionic low-osmolality CAs are used for intravenous administration in CECT examinations. As reported in several studies, the overall acute adverse reaction rate ranges from 0.2 to $3.1 \%$ of the patients. The majority of side effects are mild and non-life-threatening [18-22]. Approximately $0.04 \%$ of the patients develop serious acute reactions [22], with a fatality rate of 0.9 per 100,000 injections as reported in a meta-analysis [23].

The use of CT and also of MRI CAs is limited in patients with renal insufficiency. Contrast-induced nephropathy (CIN) develops within 48-72 h after CA injection and is defined as an increase of at least $25 \%$ in the serum creatinine level. CIN is one of the main causes of hospital-acquired renal failure and leads to a significant increase in morbidity and mortality [24-26]. A retrospective study by Davenport et al. [27] showed that the use of intravenous low-osmolarity CAs has a significant effect on the development of acute kidney injury in patients with a pre-examination serum creatinine level of $\geq 1.6$ $\mathrm{mg} / \mathrm{dl}$. Patients with creatinine levels of $<1.5 \mathrm{mg} / \mathrm{dl}$ are not at risk of developing CIN. Despite the widespread application during the last decade, there are no studies or reports showing that UCAs can cause damage to the kidneys [28]; therefore, they are considered safe in patients with renal insufficiency. 


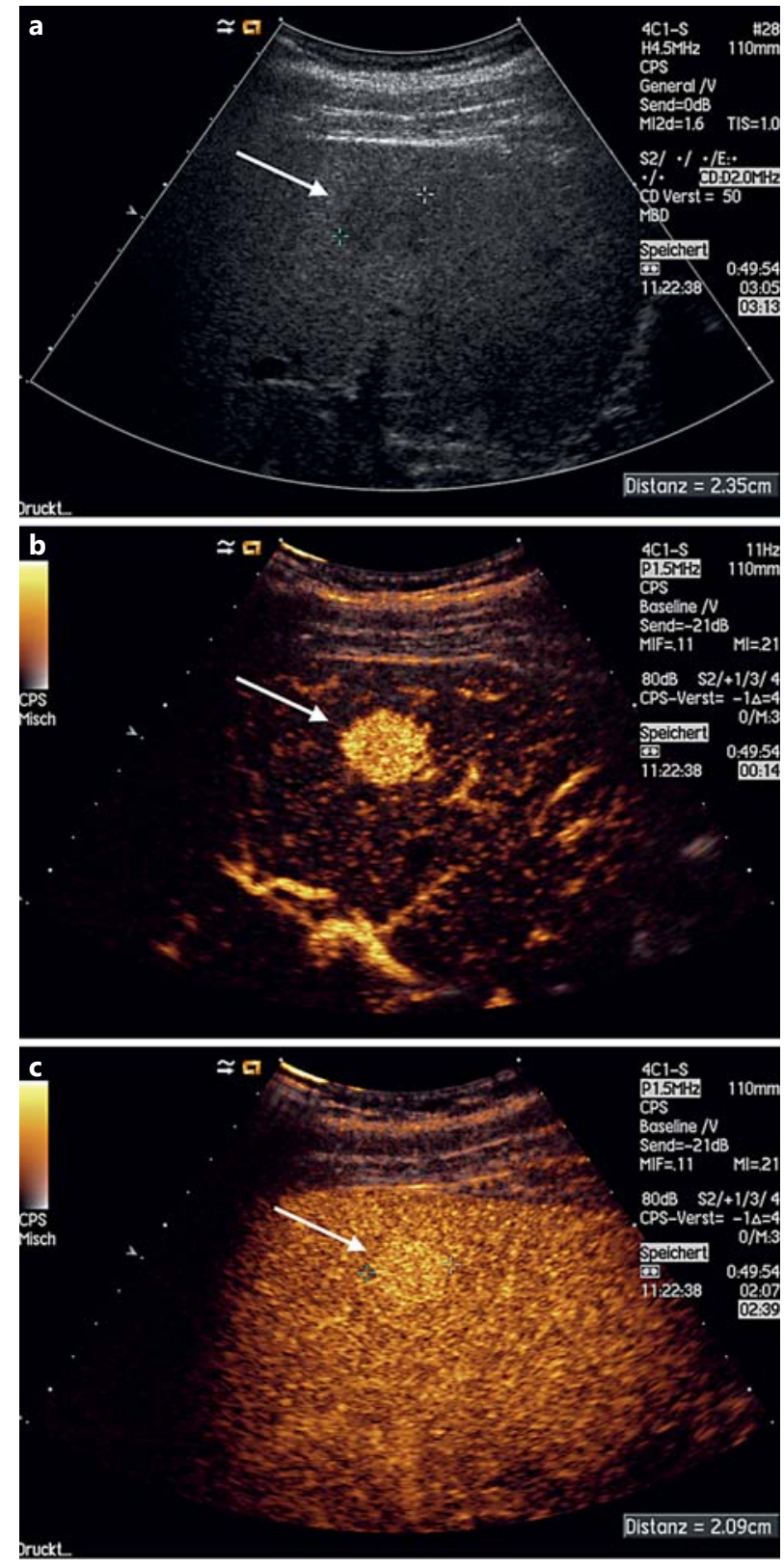

Fig. 1. Shunt hemangioma. a Hypoechoic lesion seen on gray-scale US. b Hyperenhancement during the arterial phase (14 s after intravenous CA administration). c The lesion is still enhanced during the late venous phase (160 s after intravenous CA administration), proving that it is benign.

Fig. 2. Focal nodular hyperplasia. a Discrete hypoechoic FLLs with central arterial vessel seen on color Doppler US. b, c 'Spoke-wheel' pattern of arterial centrifugal enhancement ( $26 \mathrm{~s}$ after intravenous CA administration), characteristic of a focal nodular hyperplasia. d Homogeneous enhancement (28 s after intravenous CA administration) rapidly seen after the first CA uptake within the lesion, also in favor of a focal nodular hyperplasia.
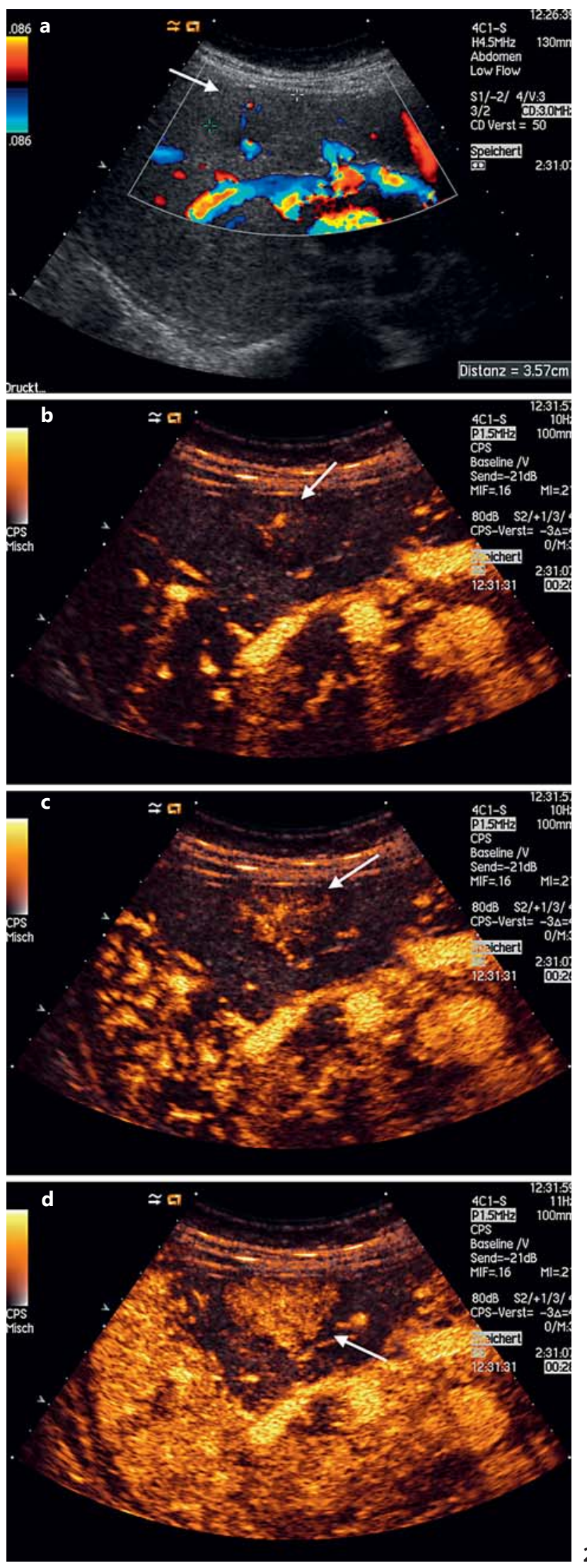

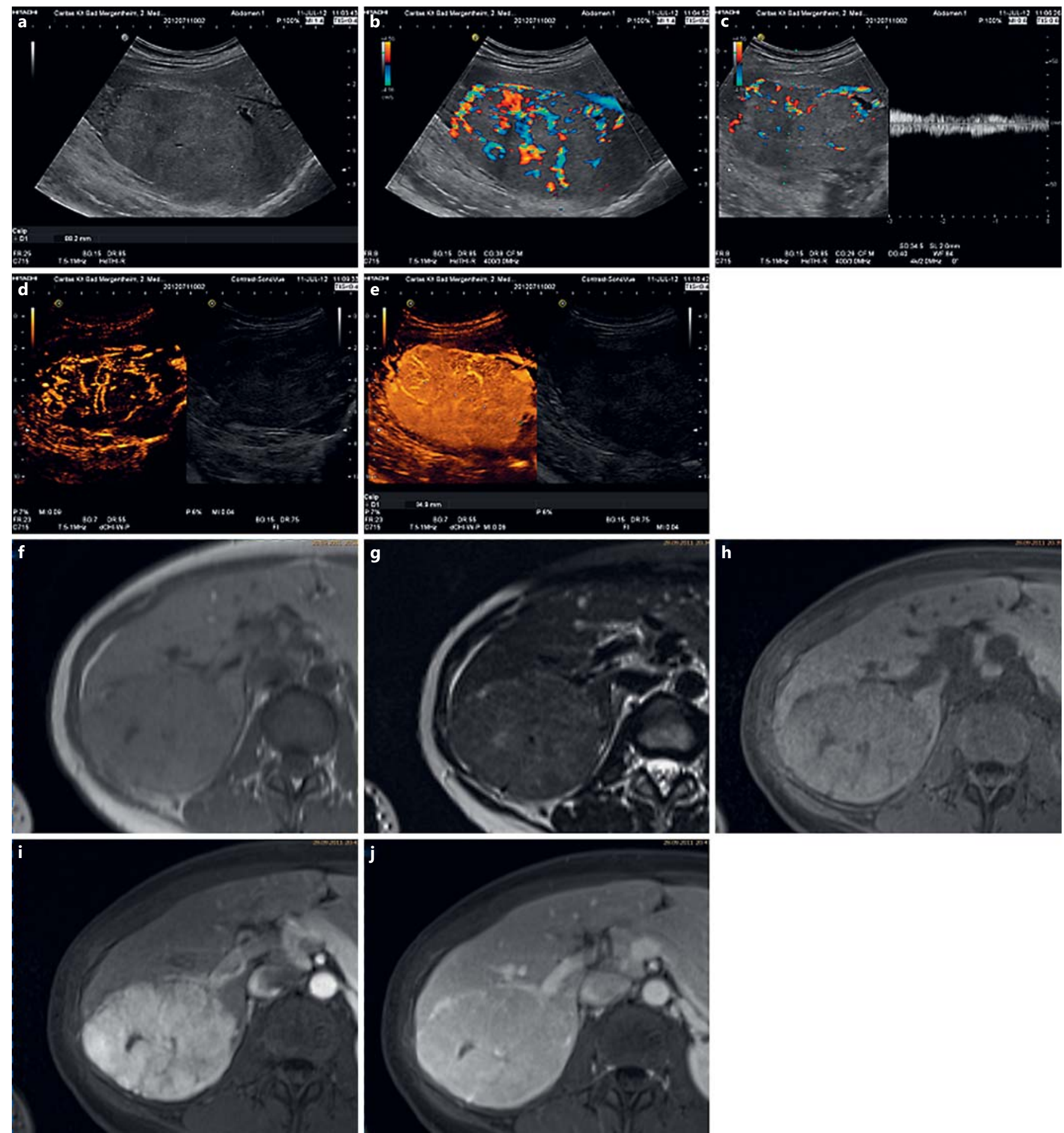

Fig. 3. Focal nodular hyperplasia. a Almost isoechoic FLL, well delineated and relatively homogeneous. b, c Highly vascularized lesion with central arterial blood supply seen on color Doppler US. d, e CEUS showing early arterial star-like centrifugal enhancement with rapid and persistent homogeneous filling. $\mathbf{f}$ T1-weighted MR image showing a slightly hypointense homogeneous FLL. g FLL

with a slightly hyperintense appearance on the T2-weighted MRI sequence and a more hyperintense central scar. $\mathbf{h}$ There is no fat suppression. i Homogeneous arterial enhancement (except for the central scar which remains unenhanced). $\mathbf{j}$ There is no washout during the portal venous phase. 


\section{Characteristics of MRI CAs}

Intravenous MRI CAs include chelates of paramagnetic ions, both ionic and nonionic. Gadolinium chelates are the most commonly used MRI contrast media and show an extracellular hepatic distribution. Another MRI CA used especially for the differential diagnosis of liver lesions is ferumoxide (Endorem ${ }^{\circledR}$ ) which contains superparamagnetic iron oxide nanoparticles that allow an imaging time of $30 \mathrm{~min}$ up to $6 \mathrm{~h}$ after administration [29]. It is a reticuloendothelial system-specific agent which improves the detection of hepatic lesions with negligible reticuloendothelial cells such as liver metastases [30, 31]. Recently, the use of gadolinium ethoxybenzyl diethylenetriamine pentaacetic acid (Gd-EOB-DTPA; Primovist ${ }^{\circledR}$ in Europe and Eovist ${ }^{\circledR}$ in the USA) further improved the detection and characterization of FLLs by CEMRI due to its progressive distribution within the hepatocytes during the so-called hepatobiliary phase $[10,32,33]$.

\section{The Safety of MRI CAs}

The CAs containing gadolinium are generally safe in healthy subjects and usually have no effect on laboratory tests, but adverse effects have been reported in some cases $[34,35]$. Out of 65,009 adults and 13,344 pediatric patients examined with gadolinium-enhanced MRI, Dillman et al. [36] reported acute allergic-like reactions in 0.07 and $0.04 \%$ of the adult and pediatric patients, respectively. The majority of acute allergic-like reactions were mild $(74 \%)$, and $50 \%$ of them occurred in patients with one or more presumed risk factors for contrast material reactions, such as a history of previous allergic-like reactions to either gadolinium or iodine-containing contrast media, a prior allergic reaction to a substance different from contrast media, or documented asthma. When exposed to gadolinium CAs, patients with severe renal failure can manifest a condition called nephrogenic systemic fibrosis which is primarily characterized by fibrosis of the skin, but it can also evolve with involvement of the skeletal muscles, heart, and lungs secondary to circulating fibrocytes which are believed to be inappropriately stimulated by gadolinium [37-41]. This condition is extremely rare but is associated with increased mortality [42].

\section{Advantages of UCAs}

The Safety of UCAs

While iodinated CAs may be associated with renal or systemic toxicity, UCAs are generally safe, with a very low incidence of side effects and without significant cardio-, hepato- or nephrotoxic effects $[28,43,44]$. In a retrospective study [28] of 23,188 investigations with second-generation UCAs $\left(\right.$ SonoVue ${ }^{\circledR}$ ), the rate of serious adverse events was only $0.0086 \%$ (29 cases), including one pseudo-anaphylactic shock and one bronchospasm, but no fatal event occurred. Death had been reported during contrast echocardiography with the UCAs Definity ${ }^{\circledR}$ and Optison ${ }^{\circledR}$, but the 4 patients concerned were critically ill, and no evidence suggested that the deaths were related to the UCAs [45]. In addition, SonoVue ${ }^{\circledR}$ is currently the most widely used UCA, while Definity ${ }^{\circledR}$ and Optison ${ }^{\circledR}$ are seldom used in hepatic US. Bio effects may be produced by the interaction of US and UCAs; however, no studies have shown that this may cause adverse effects in human organs $[2,3]$.

One advantage of UCAs is that CEUS allows an immediate evaluation of any detected or suspected FLL on B-mode US, without the need of prior laboratory testing for renal or hepatic function [5]. The risk of allergic and hypersensitivity reactions is comparable to the risk encountered with MRI CAs, and it is generally lower than that associated with X-ray CAs [28]. The excellent safety profile of UCAs allows a rapid and repeated evaluation also in the same US session when needed $[1,2,28,44,46]$.

\section{UCAs Are Strictly Intravascular}

Contrast enhancement characteristics of CEUS, CECT and CEMRI are not equivalent due to the different biochemistry and pharmacokinetics of the respective CAs. Due to their physical size, UCAs are true blood pool agents and do not diffuse outside the capillaries or other vessels, unless there is an ongoing hemorrhage. Being strictly intravascular, UCAs allow a better characterization of FLLs, especially during portal and late venous phases, and a more confident evaluation of washout phenomena compared to CT or MRI CAs, which are rapidly cleared from the blood pool into the extracellular space and may conceal washout $[1-3,6,11-17,47,48]$.

Two UCAs (Levovist ${ }^{\circledR}$ and Sonazoid ${ }^{\circledR}$ ) are taken up by Kupffer cells approximately 15 min after intravenous injection. This phase is called postvascular phase or Kupffer imaging phase [49]. UCAs like Sonazoid ${ }^{\circledR}$, which contain perflubutane microbubbles, have a more prolonged resonation period without collapsing. Thus, Kupffer imaging is stable for more than several hours, facilitating wholeliver scanning. CEUS with Sonazoid ${ }^{\circledR}$ is helpful in differentiating malignant from benign FLLs [50] and may detect hepatocellular carcinoma nodules not visible at conventional US [51]. 
The diffusion of cross-sectional CAs into the interstitium is seen in malignant but not in benign lesions, leading to the conclusion that CAs diffuse from leaky vessels of malignant lesions, differently from UCAs $[52,53]$. As discussed above, due to the strictly intravascular distribution of UCAs, CEUS allows a more prolonged enhancement than CT and MRI and also a quantitative assessment of the microcirculation [5]. This characteristic can be really helpful in the differential diagnosis of FLLs. By a time-intensity curve analysis, for example, a differentiation between focal nodular hyperplasia and liver adenoma may be possible using SonoVue ${ }^{\circledR}[54]$, which can otherwise be challenging even for histologists.

\section{No Radiation Exposure}

The estimated effective dose for adults ranges from 1 to $10 \mathrm{mSv}$ for an abdominal CT examination with CA, and from 10 to $30 \mathrm{mSv}$ for an abdominal CT examination with and without CA $[55,56]$. Since the primary risk associated with exposure to ionizing radiation is cancer, it is important to select the appropriate imaging procedure [56]. One important criterion for recommending an imaging procedure should be to reduce the radiation exposure. However, there is a large consensus that the radiation risk can be justified by obtaining useful diagnostic clues that otherwise could not be evident with other imaging procedures [57-59]. Ideally, the selection of an appropriate imaging procedure that avoids any radiation exposure should be seriously considered, and CEUS is devoid of any radiation exposure to the patient $[56,60,61]$.

The availability of an imaging method such as CEUS has improved the risk/benefit ratio in patients undergoing diagnostic contrast examinations. In the clinical setting of a patient with an FLL needing a final diagnosis and follow-up, CEUS represents an excellent alternative to CECT or CEMRI as it is better tolerated and not inferior to these techniques $[62,63]$. Therefore, CEUS examination should always be considered as a first diagnostic procedure when appropriate [52].

\section{Availability}

CEUS is a widespread technique [64]; it is portable and can be performed at the patient's bedside, in the operating room and CT suite. Moreover, it is less stressful and less invasive for the patient than CT or MRI because it does not provoke anxiety or claustrophobia [65]. Even young children often tolerate the investigation without sedation. Furthermore, it can be performed immediately after detection of FLL by baseline US. The results are better when the patients are cooperative and comply with the exami- nation, which is usually accomplished due to the nonstressful examining conditions and also due to the availability of a discussion between examiner and patient with explanatory information given to the patient during the diagnostic procedure [44].

\section{Low Cost}

The CEUS is a cost-efficient examination which is relatively inexpensive compared to conventional cross-sectional contrast-enhanced imaging techniques for the first-line diagnosis of FLLs [66]. For these reasons, it is used in many radiology departments [67-69]. If the initial identification of an FLL has been done by conventional B-mode US, the addition of CEUS in the same session is cost-effective [70]. The costs for the diagnostic workup of FLLs of unknown etiology found on conventional US may be reduced by more than $50 \%$ by using CEUS as a second imaging modality when compared to CT or MRI used for the same purpose $[71,72]$. The costs may even further be reduced if we consider that the use of $1.2 \mathrm{ml}$ of UCA is comparable, in terms of diagnostic efficacy, to a dose of $2.4-5 \mathrm{ml}$ of the same agent [73].

\section{Other CEUS Applications}

CEUS can provide excellent guidance for different invasive intraoperative procedures. CEUS has been proven to be useful in the assessment of liver tumor response to chemotherapy. Also, it can be used to differentiate tumor recurrence from the normal scarring process after surgical and ablative procedures, which normally takes place at the periphery of the ablated tissue $[74,75]$. CEUS is also useful in the differentiation of tumor recurrence from benign periablational enhancement and fibrosis [76-78]. The imaging aspect of recurrence is a focal and asymmetrical area of enhancement on the edge of the treated area. Symmetrical rim enhancement is considered to be a benign process - the imaging expression of scarring and inflammation [79]. On the other hand, immediate imaging after tumor ablation is essential in order to evaluate the success of the procedure by excluding residual tumor tissue. This can be proven by means of CEUS which has the advantage of immediate imaging if the ablation procedure has been carried out under US guidance. CEUS can identify vital tissue which can be further ablated during the same session [80]. Because of the strict intravascular characteristics of UCAs, a better delineation of the remaining foci can be obtained by CEUS than by CECT, which further influences the success of the procedure [44]. 
Other CEUS applications in the liver include evaluation of trauma [2,3], diagnosis of vascular disorders such as portal vein thrombosis, aneurysms and their complications [81], as well as detection of arteriovenous or arterioportal fistulas [82].

\section{Limitations of CEUS}

CEUS can be efficiently applied only in patients who can be optimally scanned by gray-scale US, a good quality of the two-dimensional US image being a requested condition $[2,43]$. In patients with extreme meteorism, obesity or in cases of an awkward position of the lesion that renders the CEUS image suboptimal, cross-sectional imaging techniques are mandatory $[67,83]$.

A correct diagnosis by CEUS is dependent on the operator skills and requires an extensive training for effective use [4]. The recommended way to gain experience is by observing contrast studies performed by experts in this field [2].

The use of a high mechanical index or continuous insonation must be avoided in order not to destroy the microbubbles, which can lead to false hypoenhancement and subsequently to a false diagnosis [44].

Another main limitation of CEUS compared to crosssectional imaging is that only one FLL can be evaluated at a time and repeated bolus administration of UCA is required in order to assess other FLLs. While cross-sectional imaging allows the simultaneous characterization of multiple FLLs, this is only rarely possible with CEUS because image planes and technical parameters need to be optimized for each FLL examined and the transducer has to be kept still during the examination $[43,84,85]$. However, in clinical practice, only 2 and maximally 3 FLLs located in the same segment or lobe may be simultaneously and easily examined with CEUS.

CEUS, like any other imaging modality, is subject to specific artifacts. Their knowledge is of utter importance for operators in order to avoid misinterpretation with subsequent misdiagnosis and mismanagement [86]. Problems arising from documentation, not least concerning legal issues, have long been debated and regarded as a limitation of US examinations in general.

Summarizing the limitations of CEUS, the operator dependency needs to be mentioned first [44]. Secondly, the quality of the baseline US determines the quality of CEUS and may be disappointing if the conventional US was suboptimal [2]. Furthermore, CEUS does not allow an evaluation of multiple FLLs at the same time [43]. The smallest detectable lesions range from 3 to $5 \mathrm{~mm}$ in diameter [87]; deep-seated and subdiaphragmatic lesions may not be accessible, and very small FLLs may be overlooked [2]. CEUS has a reduced sensitivity and specificity in fatty liver [2], and artifacts need to be excluded [86].

\section{Conclusions}

CEUS is an innovative and important imaging technique that can be an alternative to modalities such as CECT and CEMRI in the appropriate clinical context. The examinations should be performed by skilled operators in order to obtain excellent images and reliable results. With increasing evidence regarding the usefulness of CEUS in applications other than FLLs, CEUS is becoming largely integrated into clinical practice, thus avoiding any radiation exposure and biologic risk in patients undergoing diagnostic procedures.

\section{References}

1 Claudon M, Cosgrove D, Albrecht T, et al: Guidelines and good clinical practice recommendations for contrast enhanced ultrasound (CEUS) - update 2008. Ultraschall Med 2008;29:28-44.

-2 Claudon M, Dietrich CF, Choi BI, et al: Guidelines and good clinical practice recommendations for contrast enhanced ultrasound (CEUS) in the liver - update 2012: a WFUMB-EFSUMB initiative in cooperation with representatives of AFSUMB, AIUM, ASUM, FLAUS and ICUS. Ultraschall Med 2013;34:11-29.
- 3 Claudon M, Dietrich CF, Choi BI, et al: Guidelines and good clinical practice recommendations for contrast enhanced ultrasound (CEUS) in the liver - update 2012: a WFUMB-EFSUMB initiative in cooperation with representatives of AFSUMB, AIUM, ASUM, FLAUS and ICUS. Ultrasound Med Biol 2013;39:187-210.

$\checkmark 4$ Dietrich CF, Cui XW, Schreiber-Dietrich DG, et al: EFSUMB guidelines 2011: comments and illustrations. Ultraschall Med 2012; 33(suppl 1):S11-S21.
5 Piscaglia F, Nolsoe C, Dietrich CF, et al: The EFSUMB guidelines and recommendations on the clinical practice of contrast enhanced ultrasound (CEUS): update 2011 on non-hepatic applications. Ultraschall Med 2012;33:33-59.

6 Bauer A, Solbiati L: Ultrasound contrast agents; in Solbiati L, Martegani A, Leen E, et al (eds): Contrast-Enhanced Ultrasound of Liver Diseases. Milan, Springer, 2003, pp 21-26.

7 Brodoefel H, Kramer U, Reimann A, et al: Dual-source CT with improved temporal resolution in assessment of left ventricular function: a pilot study. AJR Am J Roentgenol 2007;189: 1064-1070. 
8 Slavin GS, Bluemke DA: Spatial and temporal resolution in cardiovascular MR imaging: review and recommendations. Radiology 2005; 234:330-338.

-9 Xue H, Kellman P, Larocca G, et al: High spatial and temporal resolution retrospective cine cardiovascular magnetic resonance from shortened free breathing real-time acquisitions. J Cardiovasc Magn Reson 2013;15:102.

10 Chiorean L, Caraiani C, Radzina M, et al: Vascular phases in imaging and their role in focal liver lesions assessment. Clin Hemorheol Microcirc 2015;62:299-326.

11 Burns PN: Contrast ultrasound technology; in Solbiati L, Martegani A, Leen E, et al (eds): Contrast-Enhanced Ultrasound of Liver Diseases. Milan, Springer, 2003, pp 1-18.

12 Correas JM, Bridal L, Lesavre A, et al: Ultrasound contrast agents: properties, principles of action, tolerance, and artifacts. Eur Radiol 2001;11:1316-1328.

13 Greis C: Technology overview: SonoVue (Bracco, Milan). Eur Radiol 2004;14(suppl 8): P11-P15.

14 Basilico R, Blomley MJ, Harvey CJ, et al: Which continuous US scanning mode is optimal for the detection of vascularity in liver lesions when enhanced with a second generation contrast agent? Eur J Radiol 2002;41: 184-191.

15 Leen E, Horgan P: Ultrasound contrast agents for hepatic imaging with nonlinear modes. Curr Probl Diagn Radiol 2003;32:66-87.

16 Bernatik T, Becker D, Neureiter D, et al: Detection of liver metastases - comparison of contrast-enhanced ultrasound using first versus second generation contrast agents (in German). Ultraschall Med 2003;24:175-179.

17 Wilson SR, Kim TK, Jang HJ, et al: Enhancement patterns of focal liver masses: discordance between contrast-enhanced sonography and contrast-enhanced CT and MRI. AJR Am J Roentgenol 2007;189:W7-W12.

18 Cochran ST, Bomyea K, Sayre JW: Trends in adverse events after iv administration of contrast media. AJR Am J Roentgenol 2001;176: 1385-1388.

19 Mortele KJ, Oliva MR, Ondategui S, et al: Universal use of nonionic iodinated contrast medium for CT: evaluation of safety in a large urban teaching hospital. AJR Am J Roentgenol 2005; 184:31-34.

20 Wang CL, Cohan RH, Ellis JH, et al: Frequency, outcome, and appropriateness of treatment of nonionic iodinated contrast media reactions. AJR Am J Roentgenol 2008; 191: 409-415.

21 Palmer FJ: The RACR survey of intravenous contrast media reactions. Final report. Australas Radiol 1988;32:426-428.

22 Katayama H, Yamaguchi K, Kozuka T, et al: Adverse reactions to ionic and nonionic contrast media. A report from the Japanese committee on the safety of contrast media. Radiology 1990;175:621-628.
23 Caro JJ, Trindade E, McGregor M: The risks of death and of severe nonfatal reactions with high- versus low-osmolality contrast media: a meta-analysis. AJR Am J Roentgenol 1991; 156:825-832.

24 Briguori C, Tavano D, Colombo A: Contrast agent-associated nephrotoxicity. Prog Cardiovasc Dis 2003;45:493-503.

25 Schrader R: Contrast material-induced renal failure: an overview. J Interv Cardiol 2005; 18: 417-423.

26 Waikar SS, Liu KD, Chertow GM: Diagnosis, epidemiology and outcomes of acute kidney injury. Clin J Am Soc Nephrol 2008;3:844861.

27 Davenport MS, Khalatbari S, Dillman JR, et al: Contrast material-induced nephrotoxicity and intravenous low-osmolality iodinated contrast material. Radiology 2013;267:94105.

28 Piscaglia F, Bolondi L: The safety of SonoVue in abdominal applications: retrospective analysis of 23,188 investigations. Ultrasound Med Biol 2006;32:1369-1375.

29 Wang YX: Superparamagnetic iron oxide based MRI contrast agents: current status of clinical application. Quant Imaging Med Surg 2011;1:35-40.

30 Bulakci M, Yilmaz E, Yahyayev A, et al: Superparamagnetic iron oxide-enhanced magnetic resonance imaging in a case of spleen hamartoma. Med Princ Pract 2013;22:301-303.

31 Jain KK: The role of nanobiotechnology in the development of personalized medicine. Med Princ Pract 2011;20:1-3.

- 32 Semelka RC, Helmberger TK: Contrast agents for MR imaging of the liver. Radiology 2001; 218:27-38.

33 Van Beers BE, Pastor CM, Hussain HK: Primovist, Eovist: what to expect? J Hepatol 2012;57:421-429.

34 Dillman JR, Ellis JH, Cohan RH, et al: Safety of gadolinium-based contrast material in sickle cell disease. J Magn Reson Imaging 2011;34:917-920.

35 Greenberger PA, Patterson R: The prevention of immediate generalized reactions to radiocontrast media in high-risk patients. J Allergy Clin Immunol 1991;87:867-872.

36 Dillman JR, Ellis JH, Cohan RH, et al: Frequency and severity of acute allergic-like reactions to gadolinium-containing i.v. contrast media in children and adults. AJR Am J Roentgenol 2007;189:1533-1538.

37 Cowper SE, Rabach M, Girardi M: Clinical and histological findings in nephrogenic systemic fibrosis. Eur J Radiol 2008;66:191-199.

38 Cowper SE, Boyer PJ: Nephrogenic systemic fibrosis: an update. Curr Rheumatol Rep 2006;8:151-157.

39 Quan TE, Cowper SE, Bucala R: The role of circulating fibrocytes in fibrosis. Curr Rheumatol Rep 2006;8:145-150.

40 Marckmann P, Skov L, Rossen K, et al: Clinical manifestation of gadodiamide-related nephrogenic systemic fibrosis. Clin Nephrol 2008;69:161-168.
41 Morris MF, Zhang Y, Zhang H, et al: Features of nephrogenic systemic fibrosis on radiology examinations. AJR Am J Roentgenol 2009; 193:61-69.

-42 Todd DJ, Kagan A, Chibnik LB, et al: Cutaneous changes of nephrogenic systemic fibrosis: predictor of early mortality and association with gadolinium exposure. Arthritis Rheum 2007;56:3433-3441.

43 Quaia E, De Paoli L, Angileri R, et al: Indeterminate solid hepatic lesions identified on non-diagnostic contrast-enhanced computed tomography: assessment of the additional diagnostic value of contrast-enhanced ultrasound in the non-cirrhotic liver. Eur J Radiol 2014;83:456-462.

44 Dietrich CF: Comments and illustrations regarding the guidelines and good clinical practice recommendations for contrast-enhanced ultrasound (CEUS) - update 2008. Ultraschall Med 2008;29(suppl 4):S188-S202.

45 Main ML, Goldman JH, Grayburn PA: Ultrasound contrast agents: balancing safety versus efficacy. Expert Opin Drug Saf 2009;8:49-56.

46 Kim TK, Lee KH, Jang HJ, et al: Analysis of gadobenate dimeglumine-enhanced MR findings for characterizing small $(1-2-\mathrm{cm})$ hepatic nodules in patients at high risk for hepatocellular carcinoma. Radiology 2011;259: 730-738.

47 Albrecht T, Blomley M, Bolondi L, et al: Guidelines for the use of contrast agents in ultrasound. January 2004. Ultraschall Med 2004;25:249-256.

48 Guang Y, Xie L, Ding H, et al: Diagnosis value of focal liver lesions with SonoVue ${ }^{\circledR}$. enhanced ultrasound compared with contrast-enhanced computed tomography and contrast-enhanced MRI: a meta-analysis. J Cancer Res Clin Oncol 2011;137:1595-1605.

49 Goto E, Masuzaki R, Tateishi R, et al: Value of post-vascular phase (Kupffer imaging) by contrast-enhanced ultrasonography using Sonazoid in the detection of hepatocellular carcinoma. J Gastroenterol 2012;47:477-485.

50 Shunichi S, Hiroko I, Fuminori M, et al: Definition of contrast enhancement phases of the liver using a perfluoro-based microbubble agent, perflubutane microbubbles. Ultrasound Med Biol 2009;35:1819-1827.

51 Hatanaka K, Kudo M, Minami Y, et al: Sonazoid-enhanced ultrasonography for diagnosis of hepatic malignancies: comparison with contrast-enhanced CT. Oncology 2008; 75(suppl 1):42-47.

52 Dietrich CF, Cui XW, Boozari B, et al: Contrast-enhanced ultrasound (CEUS) in the diagnostic algorithm of hepatocellular and cholangiocellular carcinoma, comments on the AASLD guidelines. Ultraschall Med 2012; 33(suppl 1):S57-S66.

53 Burns PN, Wilson SR: Focal liver masses: enhancement patterns on contrast-enhanced images - concordance of US scans with CT scans and MR images. Radiology 2007;242: 162-174. 
54 Dietrich CF, Schuessler G, Trojan J, et al: Differentiation of focal nodular hyperplasia and hepatocellular adenoma by contrast-enhanced ultrasound. Br J Radiol 2005;78:704707.

55 Guite KM, Hinshaw JL, Ranallo FN, et al: Ionizing radiation in abdominal CT: unindicated multiphase scans are an important source of medically unnecessary exposure. J Am Coll Radiol 2011;8:756-761.

56 ACR Appropriateness Criteria ${ }^{\circledR}$ liver lesion initial characterization. National Guideline Clearinghouse (NGC) CY. Rockville, Agency for Healthcare Research and Quality (AHRQ). www. guideline.gov/content.aspx?id=48283.

57 Malone J, Guleria R, Craven C, et al: Justification of diagnostic medical exposures: some practical issues. Report of an International Atomic Energy Agency consultation. Br J Radiol 2012;85:523-538.

58 Remedios D, Brink J, Holmberg O, et al: Clinical imaging guidelines part 1: a proposal for uniform methodology. J Am Coll Radiol 2015; 12:45-50.

59 Malone J, del Rosario-Perez M, Van Bladel L, et al: Clinical imaging guidelines part 2: risks, benefits, barriers, and solutions. J Am Coll Radiol 2015;12:158-165.

60 Goske MJ, Applegate KE, Bulas D, et al: Image gently: progress and challenges in CT education and advocacy. Pediatr Radiol 2011; 41(suppl 2):461-466.

-61 Larson PA, Bettman MA, Waldrip C: Ionizing radiation in abdominal $\mathrm{CT}$ and the ACR appropriateness criteria ${ }^{\circledR}$. J Am Coll Radiol 2012;9:298; author reply 298-299.

62 Seitz K, Bernatik T, Strobel D, et al: Contrastenhanced ultrasound (CEUS) for the characterization of focal liver lesions in clinical practice (DEGUM Multicenter Trial): CEUS versus MRI - a prospective comparison in 269 patients. Ultraschall Med 2010;31:492-499.

63 Seitz K, Strobel D, Bernatik T, et al: Contrastenhanced ultrasound (CEUS) for the characterization of focal liver lesions - prospective comparison in clinical practice: CEUS versus CT (DEGUM Multicenter Trial). Parts of this manuscript were presented at the Ultrasound Dreiländertreffen 2008, Davos. Ultraschall Med 2009;30:383-389.

64 Beaton C, Cochlin D, Kumar N: Contrast enhanced ultrasound should be the initial radiological investigation to characterise focal liver lesions. Eur J Surg Oncol 2010;36:43-46.
65 Enders J, Zimmermann E, Rief M, et al: Reduction of claustrophobia during magnetic resonance imaging: methods and design of the 'CLAUSTRO' randomized controlled trial. BMC Med Imaging 2011;11:4.

66 D’Onofrio M, Crosara S, De Robertis R, et al: Contrast-enhanced ultrasound of focal liver lesions. AJR Am J Roentgenol 2015;205:W56W66.

67 Strobel D, Seitz K, Blank W, et al: Contrastenhanced ultrasound for the characterization of focal liver lesions - diagnostic accuracy in clinical practice (DEGUM Multicenter Trial). Ultraschall Med 2008;29:499-505.

68 Seitz K, Greis C, Schuler A, et al: Frequency of tumor entities among liver tumors of unclear etiology initially detected by sonography in the noncirrhotic or cirrhotic livers of 1349 patients. Results of the DEGUM Multicenter Study. Ultraschall Med 2011;32:598-603.

69 Dai Y, Chen MH, Yin SS, et al: Focal liver lesions: can SonoVue-enhanced ultrasound be used to differentiate malignant from benign lesions? Invest Radiol 2007;42:596-603.

70 Sporea I, Sirli R, Martie A, et al: How useful is contrast enhanced ultrasonography for the characterization of focal liver lesions? J Gastrointestin Liver Dis 2010;19:393-398.

71 Romanini L, Passamonti M, Aiani L, et al: Economic assessment of contrast-enhanced ultrasonography for evaluation of focal liver lesions: a multicentre Italian experience. Eur Radiol 2007;17(suppl 6):F99-F106.

72 Faccioli N, D’Onofrio M, Comai A, et al: Contrast-enhanced ultrasonography in the characterization of benign focal liver lesions: activity-based cost analysis. Radiol Med 2007; 112:810-820.

73 von Herbay A, Westendorff J, Gregor M: Contrast-enhanced ultrasound with SonoVue: differentiation between benign and malignant focal liver lesions in 317 patients. J Clin Ultrasound 2010;38:1-9.

74 Gravante G, Ong SL, Metcalfe MS, et al: The effects of radiofrequency ablation on the hepatic parenchyma: histological bases for tumor recurrences. Surg Oncol 2011;20:237-245.

75 Gravante G, Ong SL, Metcalfe MS, et al: Hepatic microwave ablation: a review of the histological changes following thermal damage. Liver Int 2008;28:911-921.

76 Wu H, Patel RB, Zheng Y, et al: Differentiation of benign periablational enhancement from residual tumor following radio-frequency ablation using contrast-enhanced ultrasonography in a rat subcutaneous colon cancer model. Ultrasound Med Biol 2012;38:443-453.
77 Alzaraa A, Gravante G, Chung WY, et al: Contrast-enhanced ultrasound in the preoperative, intraoperative and postoperative assessment of liver lesions. Hepatol Res 2013; 43:809-819.

78 Dietrich CF, Cui XW, Chiorean L, et al: Local ablative procedures of the liver. Z Gastroenterol 2015;53:579-590.

79 Guibal A, Bertin C, Egels S, et al: Contrastenhanced ultrasound (CEUS) follow-up after radiofrequency ablation or cryoablation of focal liver lesions: treated-area patterns and their changes over time. Eur Radiol 2013;23: 1392-1400

80 Solbiati L, Ierace T, Tonolini M, et al: Guidance and monitoring of radiofrequency liver tumor ablation with contrast-enhanced ultrasound. Eur J Radiol 2004;51(suppl):S19-S23.

81 Tana C, Dietrich CF, Badea R, et al: Contrastenhanced ultrasound in portal venous system aneurysms: a multi-center study. World J Gastroenterol 2014;20:18375-18383.

82 Luo MY, Shan H, Jiang ZB, et al: Study on hepatocellular carcinoma-associated hepatic arteriovenous shunt using multidetector CT. World J Gastroenterol 2003;9:2455-2459.

83 Della Vigna P, Cernigliaro F, Monfardini L, et al: Contrast-enhanced ultrasonography in the follow-up of patients with hepatic metastases from breast carcinoma. Radiol Med 2007;112: 47-55.

84 Liu GJ, Xu HX, Xie XY, et al: Does the echogenicity of focal liver lesions on baseline grayscale ultrasound interfere with the diagnostic performance of contrast-enhanced ultrasound? Eur Radiol 2009;19:1214-1222.

85 Bartolotta TV, Taibbi A, Matranga D, et al: Hepatic focal nodular hyperplasia: contrastenhanced ultrasound findings with emphasis on lesion size, depth and liver echogenicity. Eur Radiol 2010;20:2248-2256.

86 Dietrich CF, Ignee A, Greis C, et al: Artifacts and pitfalls in contrast-enhanced ultrasound of the liver. Ultraschall Med 2014;35:108-125; quiz 126-107.

87 Leoni S, Piscaglia F, Golfieri R, et al: The impact of vascular and nonvascular findings on the noninvasive diagnosis of small hepatocellular carcinoma based on the EASL and AASLD criteria. Am J Gastroenterol 2010; 105:599-609. 